\title{
Vitamin D Levels and Disease Activity in Children with Systemic Lupus Erythematosus
}

\author{
Elif ÇOMAK, ${ }^{1}$ Sema AKMAN,,${ }^{1}$ Çağla Serpil DOĞAN,,${ }^{1}$ Mustafa KOYUN, ${ }^{1}$ \\ Arife USLU GÖKÇEOĞLU, ${ }^{1}$ Sabahat ÖZDEM² \\ ${ }^{1}$ Department of Pediatric Nephrology and Rheumatology, Medical Faculty of Akdeniz University, Antalya, Turkey \\ ${ }^{2}$ Department of Biochemistry, Medical Faculty of Akdeniz University, Antalya, Turkey
}

\begin{abstract}
Objectives: This study aims to evaluate the association between vitamin D deficiency and disease activity in children with juvenile systemic lupus erythematosus (SLE).

Patients and methods: A total of 16 children (13 girls and 3 boys; mean age 14.47 years; range 5-18) with SLE who were under followup in our clinic were included in this study. The medical records of the children along with the demographic data, disease duration, treatments received, disease activity, and 25-hydroxyvitamin D [25-(OH)D] levels were evaluated. Systemic lupus erythematosus disease activity (SLEDAI) scores were calculated on the day the serum samples were drawn.

Results: The median follow-up period was 30 (range 9 to 55) months. The mean serum vitamin D level was $22.04 \pm 16.75 \mathrm{ng} / \mathrm{ml}$. Vitamin D deficiency (serum vitamin D level of $<15 \mathrm{ng} / \mathrm{ml}$ ) was found in half of the patients. Six of them had significantly lower vitamin D levels $(\leq 10 \mathrm{ng} / \mathrm{ml}$ ). A significant negative correlation between the serum concentrations of vitamin D and the SLEDAI scores was found $(r=-0.711, p=0.002)$.

Conclusion: Our study results show that there is a strong negative association between disease activity and vitamin D deficiency in children with SLE. The vitamin D levels of these patients should be evaluated on a regular basis, and vitamin D supplements should be given, if necessary.

Keywords: Disease activity; pediatric; systemic lupus erythematosus; Vitamin D.
\end{abstract}

Vitamin $\mathrm{D}$ is an essential steroid hormone that has a primary role in mineral metabolism, skeletal health, and the immune system. ${ }^{1}$ Since an epidemic of vitamin D deficiency has recently been recognized, many publications have revealed an association between vitamin $\mathrm{D}$ deficiency and several diseases with high morbidity and mortality. ${ }^{2}$ Although the precise etiologic mechanisms are unclear, it is becoming apparent that unrecognized vitamin $\mathrm{D}$ deficiency contributes to the increasing incidence and severity of many chronic health conditions. In addition, evidence is accumulating which suggests that vitamin $\mathrm{D}$ also plays a key part in the pathogenesis and progression of autoimmunity. ${ }^{1,3}$ Vitamin D receptors are found on several immune cells, and in vitro studies have shown that vitamin $\mathrm{D}$ metabolites modulate $\mathrm{T}$ cell proliferation and dendritic cell function by inhibiting the development of T helper 1 cells (Th1) and Th17 cells while promoting the growth of Th2 and T regulatory (Treg) cells. In $\mathrm{B}$ cells, vitamin $\mathrm{D}$ inhibits antibody secretion and autoantibody production, and vitamin $\mathrm{D}$ has the overall effect of immunosuppression. ${ }^{1-3}$ 
Systemic lupus erythematosus (SLE) is a chronic, inflammatory, multisystemic autoimmune disease characterized by many cellular and humoral immunological abnormalities, and the inappropriate T-cell-dependent expansion of autoreactive B cells is considered to be crucial for the production of pathogenic autoantibodies. In the last few years, the possible role of vitamin $\mathrm{D}$ in the pathogenesis and activity of SLE has risen to new levels based on the results and observations of clinical and laboratory studies. Furthermore, in human lupus studies, it was found that 1.25-dihydroxyvitamin D3 [1.25- $(\mathrm{OH}) 2 \mathrm{D} 3]$ and its analogs inhibit polyclonal and anti-double-stranded DNA (anti-dsDNA) and immunoglobulin $\mathrm{G}$ (IgG) production by mitogenstimulated peripheral blood mononuclear cells (PBMCs). ${ }^{4}$

Multiple SLE cohorts have low vitamin D levels, ${ }^{5}$ but the physiological and clinical consequences of vitamin D deficiency in SLE are not entirely known. Although studies of 25-hydroxyvitamin D [25- $(\mathrm{OH}) \mathrm{D}]$ levels and disease activity in patients with SLE have not had consistent results, most cross-sectional studies show an inverse relationship between the levels of vitamin $\mathrm{D}$ and disease activity. ${ }^{6-12}$

Although the association between disease activity and serum levels of $25-(\mathrm{OH}) \mathrm{D}$ has been demonstrated in adults, considerably less is known about this relationship in children with SLE. The aims of this study were to evaluate the vitamin $\mathrm{D}$ status in pediatric patients with SLE and to examine whether there is an association between the serum levels of $25-(\mathrm{OH}) \mathrm{D}$ and disease activity in this autoimmune disease.

\section{PATIENTS AND METHODS}

We evaluated the medical records of 16 children (13 girls and 3 boys; mean age 14.47 years; range 5 to 18) with SLE who had an outpatient visit at our clinice between March 2011 and September 2011, and documented the demographic data, disease duration, clinical manifestations, blood pressure, disease activity, serum 25- $(\mathrm{OH}) \mathrm{D}$ levels along with other laboratory findings, medications used for SLE treatment, and use of vitamin D supplements for these pediatric patients.
The revised American College of Rheumatology (ACR) criteria was used for the diagnosis of $\mathrm{SLE},{ }^{13}$ and disease activity was determined using each patient's Systemic Lupus Erythematosus Disease Activity Index (SLEDAI) score on the day the serum samples were drawn. This score consisted of 24 weighted attributes that were grouped into the following nine domains known as organ systems (weightings in parentheses): central nervous system (8), vascular (8), renal (4), musculoskeletal (4), serosal (2), dermal (2), immunological (2), constitutional (1), and hematological (1). The sum of all of the weighted attribute scores was then used to calculate the final SLEDAI score. These ranged between 0 and 105, with 0 indicating no disease activity. ${ }^{14,15}$ Body mass index (BMI) was calculated by dividing the weight $(\mathrm{kg})$ by the square of the height $\left(\mathrm{m}^{2}\right)$, and the glomerular filtration rate (GFR) was estimated using the new Schwartz formula. ${ }^{16}$ Concentrations of 25-(OH)D of less than $15 \mathrm{ng} / \mathrm{ml}$ were considered to be at deficient levels, and this cutoff point for children has been accepted by most experts. ${ }^{17}$

The serum vitamin $\mathrm{D}$ levels were measured using the LC-20AT solvent delivery unit (Shimadzu Corporation, Tokyo, Japan), and the ImmuChrom ELISA kit (ImmuChrom GmbH, Heppenheim, Germany) was used for analysis of serum vitamin D levels. The intraassay coefficients of variation $(\mathrm{CVs})$ were $2.6 \%$ (control value $22.6 \mu \mathrm{g} / \mathrm{L}$ ) and $1.5 \%$ (control value $41.92 \mu \mathrm{g} / \mathrm{L}$ ), and the kit detection limit and upper limit of linearity were $2.32 \mu \mathrm{g} / \mathrm{L}$ and $500 \mu \mathrm{g} / \mathrm{L}$, respectively.

Statistical analysis was performed using the SPSS version 16.0 for Windows software program (SPSS Inc., Chicago, IL, USA). Furthermore, the Mann-Whitney $U$ test analysis for nonparametric data was used to compare the clinical data between the two groups, and Pearson's correlation coefficient was used to analyze any correlations between the SLEDAI and 25-(OH)D. A $p$ value of $<0.05$ was considered to be statistically significant.

\section{RESULTS}

The median follow-up period for the patients was 30 months (range 9-55). The mean serum vitamin D level was $22.04 \pm 16.75 \mathrm{ng} / \mathrm{ml}$, and vitamin D deficiency (serum vitamin $\mathrm{D}$ level 
$<15 \mathrm{ng} / \mathrm{ml}$ ) was detected in eight children (50\%), six of whom had significantly lower vitamin D levels $(<10 \mathrm{ng} / \mathrm{ml})$. The patients' demographic and baseline characteristics, SLEDAI scores, and laboratory data are presented in Tables 1 and 2.

The mean SLEDAI score was 7.2 (range 0-23), and there was a significant negative correlation between the serum 25- $(\mathrm{OH}) \mathrm{D}$ levels and both the SLEDAI scores (Figure 1) and parathyroind hormone (PTH) levels $(\mathrm{r}=0.711, \mathrm{p}=0.002$; $r=-0.59, p=0.02$, respectively). We also noted a positive correlation between the 25- $(\mathrm{OH}) \mathrm{D}$ levels and both the serum calcium and albumin levels $(\mathrm{r}=0.68, \mathrm{p}=0.01 ; \mathrm{r}=0.62, \mathrm{p}=0.008$, respectively $)$. However, no association was found between the serum 25-(OH)D levels and age, disease duration, complement component 3 (C3), estimated GFR (eGFR), serum creatinine, systolic and diastolic blood pressures, and BMI (all p>0.05).

Nine children (56.2\%) were using prednisone at the time of the study. However, no significant difference was found between the serum 25-(OH)D levels $(26.77 \pm 18.12)$ and SLEDAI scores
$(16.49 \pm 14.13)$ of either the children who used or did not use prednisone $(p=0.56$ and $p=0.13$, respectively). Additionally, seven patients (43.7\%) were using calcium and vitamin $\mathrm{D}$ supplements (equivalent to $600 \mathrm{mg}$ elemental calcium and $400 \mathrm{IU}$ or $800 \mathrm{IU}$ vitamin D) at the time of the study, and there was a significant difference between serum 25-(OH)D levels and SLEDAI score of children who used and who did not use vitamin D supplements $[33.5 \pm 3.18$ and $15.18 \pm 11.95, \mathrm{p}=0.009 ; 2(0-4)$ and 9.5 (2-23), $\mathrm{p}=0.007$, respectively].

\section{DISCUSSION}

In this study, we demonstrated that serum 25-(OH)D was significantly related to disease activity in children with SLE, and this correlation was independent of age, disease duration, C3 levels, eGFR, serum creatinine, and BMI. In addition, $50 \%$ of the children with SLE had a high incidence of vitamin D deficiency. Our findings were consistent with a large number of cross-sectional studies on vitamin D status and SLE in adults which show higher rates of vitamin D

Table 1. Demographic and clinical characteristics and laboratory data of the patients

\begin{tabular}{|c|c|c|c|c|c|c|}
\hline Parameters & $\mathrm{n}$ & $\%$ & Mean \pm SD & Mean & Median & Range \\
\hline Age (years) & & & & 14.47 & & $5-18$ \\
\hline \multicolumn{7}{|l|}{ Gender } \\
\hline Male & 13 & 18.75 & & & & \\
\hline Female & 13 & 81.25 & & & & \\
\hline Disease duration (months) & & & & & 30 & $9-55$ \\
\hline Body mass index $\left(\mathrm{kg} / \mathrm{m}^{2}\right)$ & & & $20.6 \pm 5.7$ & & & $12.86-34$ \\
\hline Systemic lupus erythematosus disease activity & & & $7.3 \pm 6.4$ & & & $0-23$ \\
\hline C3 (mg/dl) & & & $84.5 \pm 28.4$ & & & 23.3-153 \\
\hline Serum albumin $\left(\mathrm{g} / \mathrm{dL}^{*}\right)$ & & & $4.2 \pm 0.8$ & & & $2.6-5.1$ \\
\hline Serum creatinine $\left(\mathrm{mg} / \mathrm{dL}^{*}\right)$ & & & $0.6 \pm 0.2$ & & & $0.32-2.1$ \\
\hline eGFR $\left(\mathrm{mL} / \mathrm{min} / 1.73 \mathrm{~m}^{2}\right)$ & & & $114.5 \pm 22.5$ & & & $28.5-140$ \\
\hline Serum 25-(OH)D (ng/ml) & & & $22.0 \pm 16.8$ & & & $2.9-62.7$ \\
\hline Parathyroid hormone (ng/ml) & & & $40.8 \pm 21.7$ & & & $17.6-100.4$ \\
\hline \multicolumn{7}{|l|}{ Vitamin D status* } \\
\hline Severe deficiency ( 5 ng/ml) & 2 & 12.5 & & & & \\
\hline Insufficiency $(15-20 \mathrm{ng} / \mathrm{ml})$ & 0 & 0 & & & & \\
\hline Deficiency $(<15 \mathrm{ng} / \mathrm{ml})$ & 6 & 37.5 & & & & \\
\hline Sufficiency (20-100 ng/ml) & 8 & 50 & & & & \\
\hline \multicolumn{7}{|l|}{ Medications } \\
\hline Prednisone & 9 & 56.25 & & & & \\
\hline Vitamin D supplements & 7 & 43.7 & & & & \\
\hline \multicolumn{7}{|l|}{ Specific organ involvement } \\
\hline Renal involvement & 5 & 31.2 & & & & \\
\hline Hematologic involvement & 4 & 25 & & & & \\
\hline Neuropsychiatric disease & 1 & 6.2 & & & & \\
\hline Renal and pulmonary involvement & 1 & 6.2 & & & & \\
\hline Antiphospholipid antibody syndrome & 1 & 6.2 & & & & \\
\hline Mucocutaneous involvement & 3 & 18.8 & & & & \\
\hline Hematologic and pulmonary involvement & 1 & 6.2 & & & & \\
\hline
\end{tabular}




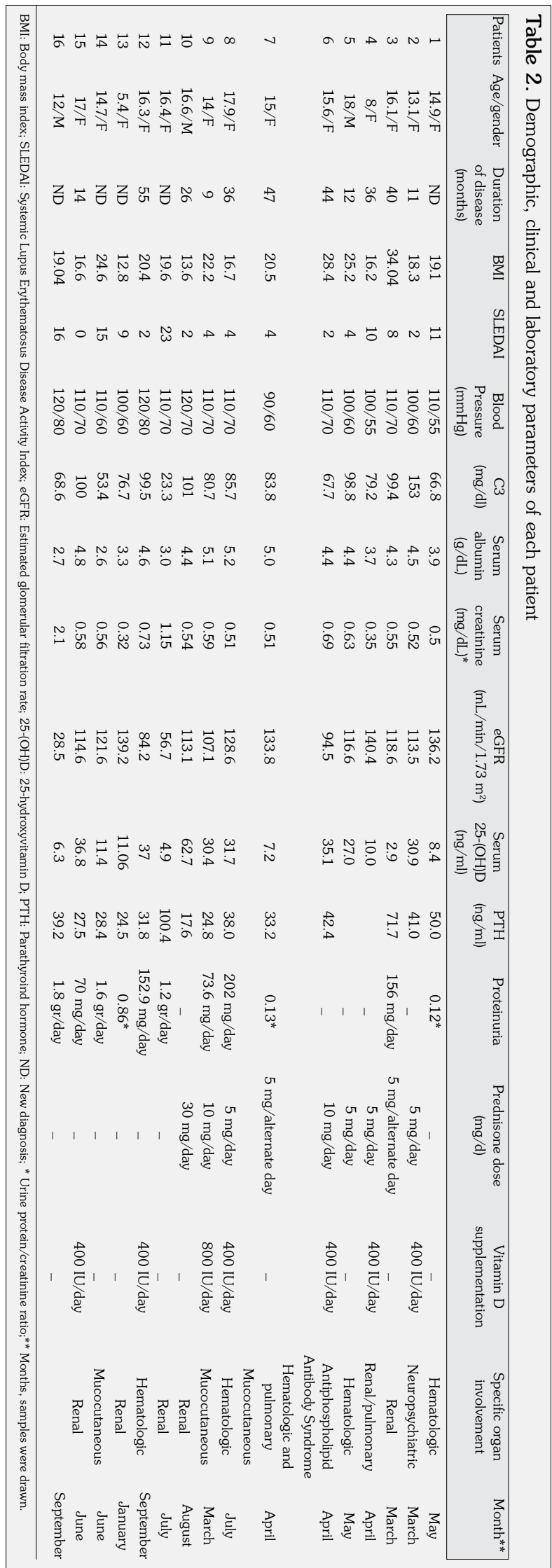

deficiency, ${ }^{11,18}$ and they also agree with other studies that identified a strong inverse relationship between 25-(OH)D levels and disease activity. ${ }^{6,8}$ However, Orbach et al. ${ }^{9}$ failed to show any correlation between disease activity and serum 25-(OH)D levels in adult patients with SLE in their study. 9

Few studies exist that have evaluated serum levels of $25-(\mathrm{OH}) \mathrm{D}$ and disease activity in SLE patients. In a study from Canada by O'Regan et al., ${ }^{19}$ seven of 12 adolescents who had SLE with a disease duration ranging from one to eight years reported low 1.25- $(\mathrm{OH}) 2 \mathrm{D} 3$ levels; however, they did not evaluate the levels of $25-(\mathrm{OH}) \mathrm{D}$, which is the best indicator of vitamin D availability. Additionally, Pelajo et al. ${ }^{7}$ reported that the mean serum $25-(\mathrm{OH}) \mathrm{D}$ levels were $21 \mathrm{ng} / \mathrm{ml}$ in 18 children with SLE, and that children with mixed connectivetissue disease and SLE had lower serum 25-(OH)D levels compared with other autoimmune disorders. They also found no association between disease activity and serum $25-(\mathrm{OH}) \mathrm{D}$ levels, which could be explained the fact that the tool they used to measure disease activity was based only on the attending physician's assessment. Moreover, Robinson et al. ${ }^{20}$ found that vitamin $\mathrm{D}$ levels were lower in patients with SLE who had proteinuria than in those who did not have this condition (11.9 and $25.0 \mathrm{ng} / \mathrm{ml}$, respectively). Moreover, they also determined that vitamin $\mathrm{D}$ levels were associated with disease activity. We did not evaluate this same association because of the small sample size and retrospective nature of our study.

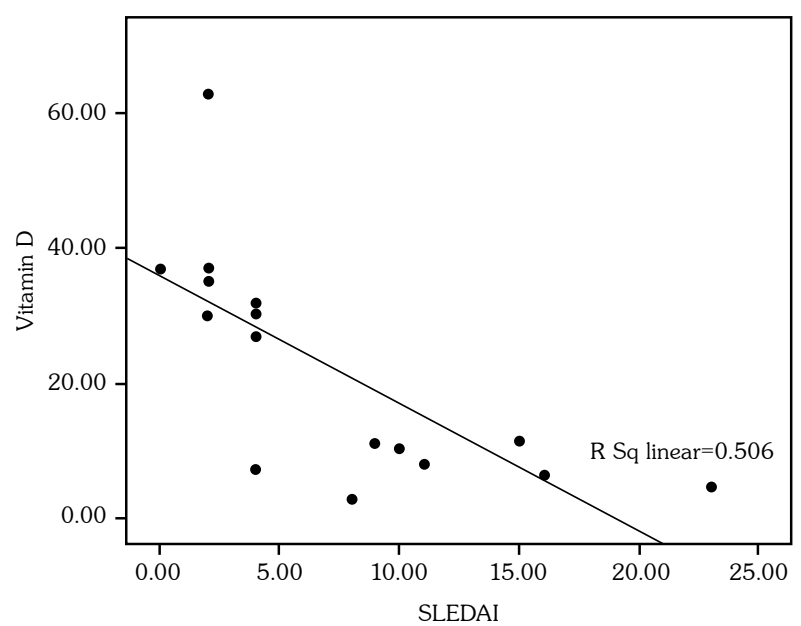

Figure 1. Significant negative correlation was found between serum vitamin $\mathrm{D}$ level and disease activity score $(\mathrm{r}=0.711, \mathrm{p}=0.002)$. SLEDAI: Systemic Lupus Erythematosus Disease Activity Index; Vitamin D: 25-(OH)D. 
Because patients with SLE have multiple risk factors for vitamin D deficiency, including longterm usage of corticosteroids, a high percentage of renal involvement, hydroxychloroquine usage, anti-vitamin D antibodies, and the need to avoid sun exposure, the prevalence of vitamin D deficiency is higher for them than for the general population. ${ }^{2,21}$ In our study, nine of the 16 children were being treated with steroids. but no significant differences were observed among the 25- $(\mathrm{OH}) \mathrm{D}$ levels and SLEDAI scores of these patients nor the seven others who were not receiving steroid treatment ( $p>0.05$ ). However, this could have been the result of the small sample size of our study or the fact that the patients taking steroids were also using vitamin $\mathrm{D}$ supplements.

Patients with SLE should avoid the sun because of photosensitive rashes and the potential for disease flare-ups; hence, adequate oral vitamin $\mathrm{D}$ supplementation is critical. ${ }^{21,22}$ In our study, six of the patients (37.5\%) were using vitamin D supplements, and a significant difference was observed in both $25-(\mathrm{OH}) \mathrm{D}$ levels and SLEDAI scores between the patients who were taking these supplements and those who were not $(\mathrm{p}=0.009$ and $\mathrm{p}=0.007$, respectively). In view of these findings, in spite of the limited number of study participants, we believe that regular screening of serum $25-(\mathrm{OH}) \mathrm{D}$ levels in children with SLE should be performed and that vitamin $\mathrm{D}$ supplementation should be given if necessary.

Recently, vitamin D deficiency has been recognized as a global health problem and can now be detected in patients of all ages. ${ }^{2}$ Therefore, controlled trials with healthy control groups are needed to evaluate the role of vitamin D on SLE. In a study of 36 lupus patients (12 with high activity and 24 with minimal activity), the subgroup of patients with high activity had significantly lower vitamin D levels than the healthy controls. ${ }^{10}$ To the best of our knowledge, there have been no controlled studies regarding this topic that have focused on children.

Our study had several limitations, including its retrospective nature, the small sample size, and lack of available information about diet, sun exposure, and use of sunscreens, all of which may have influenced the serum $25-(\mathrm{OH}) \mathrm{D}$ levels. Therefore, it could be speculated that the low levels of $25-(\mathrm{OH}) \mathrm{D}$ in the SLE patients in our study might stem from the risk factors, which would mean that they were not the source of the disease activity.

\section{Conclusion}

Vitamin D deficiency is quite common in children with SLE, and our findings indicated that $25-(\mathrm{OH})$ $\mathrm{D}$ levels had a strong inverse relationship to disease activity. The causality of these associations still needs to be assessed via longitudinal studies aimed at evaluating the therapeutic value of vitamin $\mathrm{D}$ supplementation.

\section{Declaration of conflicting interests}

The authors declared no conflicts of interest with respect to the authorship and/or publication of this article.

\section{Funding}

The authors received no financial support for the research and/or authorship of this article.

\section{REFERENCES}

1. Arnson Y, Amital H, Shoenfeld Y. Vitamin D and autoimmunity: new aetiological and therapeutic considerations. Ann Rheum Dis 2007;66:1137-42.

2. Holick MF. Vitamin D deficiency. N Engl J Med 2007;357:266-81.

3. Kamen DL. Vitamin D in lupus - new kid on the block? Bull NYU Hosp Jt Dis 2010;68:218-22.

4. Linker-Israeli M, Elstner E, Klinenberg JR, Wallace DJ, Koeffler HP. Vitamin D(3) and its synthetic analogs inhibit the spontaneous in vitro immunoglobulin production by SLE-derived PBMC. Clin Immunol 2001;99:82-93.

5. Kamen DL, Cooper GS, Bouali H, Shaftman SR, Hollis BW, Gilkeson GS. Vitamin D deficiency in systemic lupus erythematosus. Autoimmun Rev 2006;5:114-7.

6. Amital H, Szekanecz Z, Szücs G, Dankó K, Nagy E, Csépány $\mathrm{T}$, et al. Serum concentrations of $25-\mathrm{OH}$ vitamin $\mathrm{D}$ in patients with systemic lupus erythematosus (SLE) are inversely related to disease activity: is it time to routinely supplement patients with SLE with vitamin D? Ann Rheum Dis 2010;69:1155-7.

7. Pelajo CF, Lopez-BenitezJM, MillerLC. 25-hydroxyvitamin $\mathrm{D}$ levels and vitamin $\mathrm{D}$ deficiency in children with rheumatologic disorders and controls. J Rheumatol 2011;38:2000-4.

8. Bonakdar ZS, Jahanshahifar L, Jahanshahifar F, Gholamrezaei A. Vitamin D deficiency and its association with disease activity in new cases of systemic lupus erythematosus. Lupus 2011;20:1155-60.

9. Orbach H, Zandman-Goddard G, Amital H, Barak V, Szekanecz Z, Szucs G, et al. Novel biomarkers in autoimmune diseases: prolactin, ferritin, vitamin $\mathrm{D}$, and TPA levels in autoimmune diseases. Ann N Y Acad Sci 2007;1109:385-400. 
10. Borba VZ, Vieira JG, Kasamatsu T, Radominski SC, Sato EI, Lazaretti-Castro M. Vitamin D deficiency in patients with active systemic lupus erythematosus. Osteoporos Int 2009;20:427-33.

11. Cutolo M. Vitamin D and autoimmune rheumatic diseases. Rheumatology (Oxford) 2009;48:210-2.

12. Toloza SM, Cole DE, Gladman DD, Ibañez D, Urowitz MB. Vitamin D insufficiency in a large female SLE cohort. Lupus 2010;19:13-9.

13. Hochberg MC. Updating the American College of Rheumatology revised criteria for the classification of systemic lupus erythematosus. Arthritis Rheum 1997;40:1725.

14. Bombardier C, Gladman DD, Urowitz MB, Caron D, Chang $\mathrm{CH}$. Derivation of the SLEDAI. A disease activity index for lupus patients. The Committee on Prognosis Studies in SLE. Arthritis Rheum 1992;35:630-40.

15. Brunner HI, Silverman ED, Bombardier C, Feldman BM. European Consensus Lupus Activity Measurement is sensitive to change in disease activity in childhoodonset systemic lupus erythematosus. Arthritis Rheum 2003;49:335-41.

16. Schwartz GJ, Muñoz A, Schneider MF, Mak RH, Kaskel F, Warady BA, et al. New equations to estimate GFR in children with CKD. J Am Soc Nephrol 2009;20:629-37.
17. Misra M, Pacaud D, Petryk A, Collett-Solberg PF, Kappy M; Drug and Therapeutics Committee of the Lawson Wilkins Pediatric Endocrine Society. Vitamin $\mathrm{D}$ deficiency in children and its management: review of current knowledge and recommendations. Pediatrics 2008;122:398-417.

18. Ruiz-Irastorza G, Egurbide MV, Olivares N, MartinezBerriotxoa A, Aguirre C. Vitamin D deficiency in systemic lupus erythematosus: prevalence, predictors and clinical consequences. Rheumatology (Oxford) 2008;47:920-3.

19. O'Regan S, Chesney RW, Hamstra A, Eisman JA, O'Gorman AM, Deluca HF. Reduced serum 1,25-(OH)2 vitamin D3 levels in prednisone-treated adolescents with systemic lupus erythematosus. Acta Paediatr Scand 1979;68:109-11.

20. Robinson AB, Thierry-Palmer M, Gibson KL, Rabinovich $\mathrm{CE}$. Disease activity, proteinuria, and vitamin $\mathrm{D}$ status in children with systemic lupus erythematosus and juvenile dermatomyositis. J Pediatr 2012;160:297-302.

21. Kamen DL, Aranow C. The link between vitamin $\mathrm{D}$ deficiency and systemic lupus erythematosus. Curr Rheumatol Rep 2008;10:273-80.

22. Cutolo M, Otsa K. Review: vitamin D, immunity and lupus. Lupus 2008;17:6-10. 